Research Article

\title{
Rising incidence of rectal carcinoma in the young age "is it a concern?" an Indian perspective
}

\begin{abstract}
Background: As the incidence of colorectal cancer shows a steady decline in people older than 50 years, recent studies indicate a rising incidence in young individuals. This age group presents in an advanced stage, with reportedly poorer prognosis and lower survival. Lack of screening and delay in diagnosis in this group is a serious concern all over the world and particularly in India.
\end{abstract}

Aim: We aimed to study the differences between the two groups, in the tumor characteristics, responses to treatment, sphincter saving rates, recurrences and survival.

Patients \& Methods: 246 rectal cancer patients who were referred to the radiation department, between January 2010 and December 2015 were retrospectively analyzed from hospital data bases.

Results: Young patients $(52.84 \%)$ were characterized by advanced stage at diagnosis, more aggressive histology. After neo-adjuvant chemotherapy radiotherapy (NACTRT) radiological down staging in young vs old was $45.45 \%$ and $40 \%$ while pathological down staging to pT0N0 was $16.48 \%$ and $10.91 \%$. There was a significant correlation between pathological tumor and nodal status and the radiological response to NACTRT. No difference in the disease free survival (DFS) and overall survival (OS) was found between the age groups. The overall rate of sphincter preservation was $38.2 \%$. Carcinoembryonic Antigen (CEA) levels, nodal status and clinical stage at presentation were the factors that affected DFS and OS and not younger age.

Conclusion: There was no significant differences in either DFS or OS between the younger and the older patients in our study although the radiological and pathological down staging to NACTRT was more in the young. Given the higher comorbidities and lesser likelihood of completing their treatment in older individuals, the younger patients can probably have a better survival if they are diagnosed earlier at a less advanced stage.
Volume 8 Issue 4 - 2017

\section{Swarupa Mitra, Parveen Ahlawat, Manoj Sharma, Inderjeet Kaur Wahi, Ruparna Khurana, Shweta Sharma, Raman Narang, Soumya Dutta, Avik Manadal}

Department of Radiation Oncology, Rajiv Gandhi Cancer Institute and Research Centre, India

Correspondence: Dr. Swarupa Mitra, Senior Consultant, Chief- Gastrointestinal and Genitourinary Radiation Oncology, Rajiv Gandhi Cancer Institute and research Centre, Sector 5, Rohini, Delhi I I0085, India, Tel 971704I602, Emailswarupamitra@gmail.com, swarupamitra@rediffmail.com

Received: June 12, 2017 | Published: August 29, 2017

\section{Introduction}

Colorectal carcinoma, a cancer of the developed world, is one of the most common malignancies of the gastrointestinal tract. It typically affects the elderly population with over $90 \%$ of the patients affected being above 55years of age. ${ }^{1}$ However, in the last few years, the incidence in younger adults has been on the rise. Changing lifestyle, obesity, physical inactivity, intake of diet rich in processed foods with insufficient amount of fruits and vegetables, as well as the lack of screening in the young may be some reasons for this disturbing trend. Globally, 1.4 million new cases of colorectal cancers (CRC) and almost 694,000 deaths have been estimated to have occurred in 2012, which makes it the third and second most common cancer in males and females, respectively. ${ }^{2}$ Approximately 135,430 new cases of colon cancer are diagnosed every year in the United States, of which 95,520 are colon and the rest are rectal cancers.

About 50,260 Americans die of CRC annually, which accounts for almost 8 percent of all cancer deaths. ${ }^{3}$ Compared to the West, a higher incidence of CRC has been reported in young individuals in South and Southeast Asia. ${ }^{4}$ In India, the burden of colorectal carcinoma has been increasing due to probably changes in dietary habits and adoption of western lifestyles. The diagnosis is often delayed due to the rarity of this disease in the young and the low index of clinical suspicion. ${ }^{5}$ Rectal cancers in the young are characterized by presence of poorly differentiated cells, cells with mucinous and signet ring features, and are hence associated with aggressive behavior and unfavorable prognosis. ${ }^{6}$ Screening plays a vital role in early detection. ${ }^{7}$ In this review we will discuss the tumor features, treatment modalities and response, sphincter saving rates and survival outcomes of rectal carcinoma in the young and the old and deliver a comparison.

\section{Patients and methods}

Case records were retrieved for all patients diagnosed with cancer of the rectum who were treated at the Rajiv Gandhi Cancer Institute and Research Centre, New Delhi, India, from January 2010 to December 2015. Information regarding each patient's demography, clinical findings, treatments, and follow-up details was collected using an electronic data system (HIS VISTA).

\section{Inclusion and exclusion criteria}

All patients of 15 to 80 years of age with biopsy confirmed diagnosis of adenocarcinoma of the rectum were included in the present study. Patients showing involvement of colon, and those with squamous cell carcinoma or metastatic disease at presentation were excluded from the study.

\section{Institutional management approach}

After complete history and physical examination, all patients underwent colonoscopy and biopsy, magnetic resonance imaging (MRI) of the pelvis, routine hematological investigations including complete blood count and chemistry, and serum carcino embryonic 
antigen (CEA) measurements. Metastatic work up consisted of positron emission tomography (PET) scan, which was used for radiation planning as well.

All the patients had been initially reviewed by the surgeon for operability and planning of prospective surgery before being referred for neo-adjuvant chemo-radiotherapy (NACTRT) with 50.4Gy in 28 fractions of radiotherapy at $1.8 \mathrm{~Gy}$ per fraction. They were treated five days a week for five and a half weeks concomitantly with continuous IV infusion of 5-fluorouracil (5-FU) during the first and last 5 days of radiotherapy. Patients were evaluated for response to neo-adjuvant therapy six weeks after the completion of NACTRT preferably with PET, MRI, and colonoscopy. Patients were evaluated for surgery, either low anterior resection (LAR) or abdomino-perineal resection (APR) depending upon the response to neo-adjuvant therapy and the distance of the distal edge of the tumor from the anal verge. Postoperative treatment consisted of adjuvant chemotherapy with six cycles of 5-FU based regimen, followed by three monthly reviews.

\section{End points}

For the purpose of statistical analysis, all patients were divided into two groups based on the age at diagnosis. The cutoff age was 50 years. Young onset rectal cancer included patients aged 50 or less, while those older than 50 were classified as old onset. These two groups were compared in terms of demographics, clinical presentation, histological features, response to therapy, extent of sphincter preservation, surgery, and survival outcomes.

The study endpoints were presence of recurrent disease (locoregional or distant), death, or last follow-up. Disease-free survival (DFS) was defined as the time from the date of the last treatment to the date of recurrence/death or last follow-up. Overall survival (OS) was defined as time from the date of the last treatment to the date of death or last follow-up.

\section{Statistical analysis}

All statistical analyses were performed using statistical package for the social science system (SPSS version 20, SPSS Inc, Chicago, IL, USA), and $\mathrm{P}$ value $<0.05$ was considered statistically significant. All $\mathrm{P}$ values reported represent two-sided tests. Baseline patient, tumor and treatment related characteristics were expressed as frequencies along with respective percentages and were compared between treatment groups using Chi-squared test or Fisher's exact test as appropriate.

The comparisons of normally distributed continuous variables between the groups were performed using independent " $\mathrm{t}$ " test. The endpoints DFS and OS were calculated by the Kaplan-Meier product-limit method. Log-rank test was used to compare DFS and OS between the two groups. Multivariate Cox proportional hazards regression analysis was performed to estimate the impact of known relevant prognostic factors on DFS and down-staging.

\section{Results}

Patient and disease-related pretreatment characteristics were found to be matched evenly between the two groups except grade of tumor, pretreatment nodal involvement (more common in younger individuals) and adjuvant chemotherapy (more frequently administered in younger individuals) (Table 1).

Table I Comparison of patient, tumor and treatment related characteristics between young and old group

\begin{tabular}{|c|c|c|c|c|}
\hline \multirow{3}{*}{ Variable } & \multirow{3}{*}{ Category } & Younger & Older & \multirow{3}{*}{$\mathbf{P}$ value } \\
\hline & & {$[\leq 50$ yrs $]$} & [> 50 yrs $]$ & \\
\hline & & $\mathbf{N}=130$ & $N=116$ & \\
\hline \multirow{2}{*}{ Sex } & Male & $83(63.8 \%)$ & $80(68.9 \%)$ & \multirow{2}{*}{0.397} \\
\hline & Female & 47 (36.1%) & $36(31.0 \%)$ & \\
\hline \multirow{2}{*}{ Age in years } & Median (Range) & $37.50(16-50)$ & $61.0(50-89)$ & NA \\
\hline & Mean (SD) & $36.75(9.627)$ & $62.76(8.08)$ & NA \\
\hline \multirow{2}{*}{ Co-morbidities } & Present & $10(7.69 \%)$ & 18 (I5.5 \%) & \multirow{2}{*}{0.054} \\
\hline & Absent & 120 (92.3 \%) & 98 (84.4 \%) & \\
\hline \multirow{2}{*}{ Family history of CRC } & No & 121 (93\%) & II 3 (97.4 \%) & \multirow{2}{*}{0.115} \\
\hline & Yes & $9(6.92 \%)$ & $3(2.58 \%)$ & \\
\hline \multirow{5}{*}{ Symptoms } & Bleeding PR & $58(44.6 \%)$ & 47 (40.5 \%) & \multirow{5}{*}{0.132} \\
\hline & Pain & $10(7.69 \%)$ & $6(5.17 \%)$ & \\
\hline & Altered bowel habits & $7(5.38 \%)$ & $3(2.58 \%)$ & \\
\hline & Others & 51 (39.23 \%) & 48 (4I.3 \%) & \\
\hline & Unknown & $4(3.07 \%)$ & $12(10.3 \%)$ & \\
\hline \multirow{4}{*}{ Distance from anal verge $(\mathrm{cm})$} & Mean (SD) & 5.01 (30.39) & $5.16(4.22)$ & 0.759 \\
\hline & Median (Range) & $5.0(0-16)$ & $4.50(0-20)$ & 0.759 \\
\hline & $<6 \mathrm{~cm}$ & 51 (39.2\%) & 47 (4I.3 \%) & \multirow[t]{3}{*}{0.837} \\
\hline & $\geq 6 \mathrm{~cm}$ & 79 (60.7 \%) & $69(59.4 \%)$ & \\
\hline \multirow{4}{*}{ Histological Grade } & WD & 14 (10.76\%) & $9(7.75 \%)$ & \\
\hline & MD & 61 (46.9\%) & $59(50.86 \%)$ & \multirow{3}{*}{0.032} \\
\hline & PD & 17 (13.0\%) & $4(3.44 \%)$ & \\
\hline & Unknown & $38(29.2 \%)$ & $44(37.9 \%)$ & \\
\hline \multirow{2}{*}{ CEA level } & Median (Range) & $4.39(0.3-4700)$ & $4.34(0.04-590)$ & 0.894 \\
\hline & Mean (SD) & 71.33 (432.89) & $49.03(333.46)$ & \multirow[t]{3}{*}{0.654} \\
\hline \multirow{5}{*}{ cT Stage } & cTI & I $(0.76 \%)$ & $3(2.58 \%)$ & \\
\hline & cT2 & $19(14.6 \%)$ & $22(18.9 \%)$ & \\
\hline & cT3 & 91 (70 \%) & 70 (60.3 \%) & \multirow[t]{3}{*}{0.506} \\
\hline & cT4 & 15 (I I.5\%) & 16 (I3.7 \%) & \\
\hline & cTx & $4(3.07 \%)$ & $5(4.31 \%)$ & \\
\hline
\end{tabular}


Table continued...

\begin{tabular}{|c|c|c|c|c|}
\hline \multirow{3}{*}{ Variable } & \multirow{3}{*}{ Category } & Younger & Older & \multirow{3}{*}{$P$ value } \\
\hline & & {$[\leq \mathbf{5 0}$ yrs $]$} & [> $50 \mathrm{yrs}]$ & \\
\hline & & $N=130$ & $N=116$ & \\
\hline cT Stage Group & cTI, 2 & $20(15.8 \%)$ & $25(22.5 \%)$ & \multirow[t]{3}{*}{0.193} \\
\hline \multirow[t]{2}{*}{$(n=237)$} & cT3,4 & $106(84.1 \%)$ & 86 (77.4 \%) & \\
\hline & cNO & $33(25.3 \%)$ & 52 (44.8 \%) & \\
\hline \multirow{3}{*}{ cN Stage } & $\mathrm{cNI}$ & 61 (46.9\%) & 52 (44.8 \%) & \multirow{3}{*}{0} \\
\hline & $\mathrm{cN} 2$ & 32 (24.6 \%) & 7 (6.03\%) & \\
\hline & $\mathrm{cNx}$ & $4(3.07 \%)$ & $5(4.31 \%)$ & \\
\hline cN Group & Nodes Absent & 33 (26.1 \%) & $52(46.8 \%)$ & \multirow[t]{2}{*}{0.001} \\
\hline$(n=237)$ & Nodes Present & 93 (73.8 \%) & $59(53.1 \%)$ & \\
\hline \multirow{2}{*}{ Underwent RT } & Yes & $126(96.9 \%)$ & $112(96.5 \%)$ & \multirow{2}{*}{1} \\
\hline & No & $4(3.07 \%)$ & $4(3.44 \%)$ & \\
\hline \multirow{3}{*}{ Surgery Planned } & APR & $93(71.5 \%)$ & 78 (67.2 \%) & \multirow{3}{*}{0.465} \\
\hline & LAR & $37(28.4 \%)$ & 38 (32.7 \%) & \\
\hline & APR & 43 (33.8 \%) & 29 (25 \%) & \\
\hline \multirow[t]{2}{*}{ Surgery Performed } & LAR & 48 (36.9\%) & $43(37.0 \%)$ & \multirow[t]{2}{*}{0.222} \\
\hline & No Surgery & 38 (29.2 \%) & 44 (37.9 \%) & \\
\hline \multirow{2}{*}{ Chemotherapy } & Yes & $91(70 \%)$ & 65 (56.0 \%) & \multirow{2}{*}{0.023} \\
\hline & No & 39 (30 \%) & $5 \mathrm{I}(43.9 \%)$ & \\
\hline
\end{tabular}

\section{Radiological response}

Analyzing those patients who had undergone response evaluation after NACTRT, results showed that NACT RT elicited a significant shift towards down staging of disease; $45.8 \%$ patients achieved tumour (T) downsizing, $\mathrm{p}=0.000$ (Table 2), 56.2\% patients achieved nodal (N) downsizing, $\mathrm{p}=0.000$ (Table 3 ), and $50.0 \%$ patients achieved clinical stage downsizing, $\mathrm{p}=0.000$. There was no significant difference in tumour (T) down-staging after NACTRT between younger and older individuals $(45.45 \%$ vs $40 \%$ respectively, $\mathrm{p}=0.677)$. However, there was significantly lesser nodal $(\mathrm{N})$ downsizing in younger compared with older individuals $(27.27 \%$ vs $56 \%$; $=0.026)$ after NACTRT. There was no significant difference in clinical stage down-staging after NACTRT between younger individuals and older individuals $(33.33 \%$ vs $64 \%$ respectively, $\mathrm{p}=0.152)$.

Table 2 Correlation between cT Stage and ycT Stage $(\mathrm{N}=159)$

\begin{tabular}{|c|c|c|c|c|c|c|c|c|}
\hline \multicolumn{9}{|c|}{ T Stage after NACT/RT (ycT) } \\
\hline \multicolumn{2}{|c|}{ Clinical T Staging } & уст 0 & ycT I & yсT 2 & ycT 3 & ycT 4 & Unknown & Grand Total \\
\hline \multirow{2}{*}{ cT I } & $\mathrm{N}$ & I & I & 0 & 0 & 0 & 0 & 2 \\
\hline & $\%$ & $50.00 \%$ & $50.00 \%$ & $0.00 \%$ & $0.00 \%$ & $0.00 \%$ & $0.00 \%$ & $100.00 \%$ \\
\hline \multirow{2}{*}{ cT 2} & $\mathrm{~N}$ & 0 & 2 & 2 & 2 & 0 & 21 & 27 \\
\hline & $\%$ & $0.00 \%$ & $7.41 \%$ & $7.41 \%$ & $7.41 \%$ & $0.00 \%$ & $77.78 \%$ & $100.00 \%$ \\
\hline \multirow{2}{*}{ cT 3} & $\mathrm{~N}$ & 8 & 7 & 5 & 13 & I & 74 & 108 \\
\hline & $\%$ & $7.41 \%$ & $6.48 \%$ & $4.63 \%$ & $12.04 \%$ & $0.93 \%$ & $68.52 \%$ & $100.00 \%$ \\
\hline \multirow{2}{*}{ cT 4} & $\mathrm{~N}$ & 0 & 1 & 2 & 3 & 0 & 14 & 20 \\
\hline & $\%$ & $0.00 \%$ & $5.00 \%$ & $10.00 \%$ & $15.00 \%$ & $0.00 \%$ & $70.00 \%$ & $100.00 \%$ \\
\hline \multirow{2}{*}{ cT $x$} & $\mathrm{~N}$ & 0 & 0 & I & 0 & 0 & I & 2 \\
\hline & $\%$ & $0.00 \%$ & $0.00 \%$ & $50.00 \%$ & $0.00 \%$ & $0.00 \%$ & $50.00 \%$ & $100.00 \%$ \\
\hline \multirow{2}{*}{ Grand Total } & $\mathrm{N}$ & 9 & II & 10 & 18 & I & 110 & 159 \\
\hline & $\%$ & $5.66 \%$ & $6.92 \%$ & $6.29 \%$ & $11.32 \%$ & $0.63 \%$ & $69.18 \%$ & $100.00 \%$ \\
\hline
\end{tabular}

Table 3 Correlation between cN Stage and ycN Stage $(N=159)$

\begin{tabular}{|c|c|c|c|c|c|c|}
\hline \multicolumn{7}{|c|}{ Nodal Staging After NACT/RT (ycN) } \\
\hline \multicolumn{2}{|c|}{ Clinical Nodal Staging } & \multirow{2}{*}{$\begin{array}{l}\text { ycN } 0 \\
16\end{array}$} & \multirow{2}{*}{$\begin{array}{l}\text { ycN I } \\
0\end{array}$} & \multirow{2}{*}{$\begin{array}{l}\text { ycN } 2 \\
0\end{array}$} & \multirow{2}{*}{$\begin{array}{l}\text { Unknown } \\
45\end{array}$} & \multirow{2}{*}{$\begin{array}{l}\text { Grand Total } \\
61\end{array}$} \\
\hline & $\mathrm{N}$ & & & & & \\
\hline cNo & $\%$ & $26.23 \%$ & $0.00 \%$ & $0.00 \%$ & $73.77 \%$ & $100.00 \%$ \\
\hline \multirow{2}{*}{$\mathrm{cN}$ I } & $\mathrm{N}$ & 15 & 12 & & 43 & 70 \\
\hline & $\%$ & $21.43 \%$ & $17.14 \%$ & $0.00 \%$ & $61.43 \%$ & $100.00 \%$ \\
\hline \multirow{2}{*}{$\mathrm{cN} 2$} & $\mathrm{~N}$ & 2 & I & 2 & 20 & 25 \\
\hline & $\%$ & $8.00 \%$ & $4.00 \%$ & $8.00 \%$ & $80.00 \%$ & $100.00 \%$ \\
\hline \multirow{2}{*}{$\mathrm{cN} x$} & $\mathrm{~N}$ & I & 0 & 0 & 2 & 3 \\
\hline & $\%$ & $33.33 \%$ & $0.00 \%$ & $0.00 \%$ & $66.67 \%$ & $100.00 \%$ \\
\hline \multirow{2}{*}{ Grand Total } & $\mathrm{N}$ & 34 & 13 & 2 & 110 & 159 \\
\hline & $\%$ & $21.38 \%$ & $8.18 \%$ & $1.26 \%$ & $69.18 \%$ & $100.00 \%$ \\
\hline
\end{tabular}




\section{Pathological Response}

Analyzing those patients who underwent surgery following NACTRT, Wilcoxon signed ranks test was run to determine the correlation between histopathological findings and post NACTRT response. Results showed that there was significant correlation between pathological T stage (ypT) and post NACTRT T stage (ycT) $(\mathrm{z}=-2.032, \mathrm{p}=0.042)$ (Table 4). When compared with pathological $\mathrm{T}$ staging after NACTRT, MRI achieved 25\%, 82.50\%, 22.22\% and $84.62 \%$ sensitivity, specificity, PPV and NPV respectively with
$72.91 \%$ accuracy for rectal tumor. There was significant correlation between pathological N stage (ypN) and post NACTRT N stage (ycT) $(\mathrm{z}=-1.964, \mathrm{p}=0.050)($ Table 4$)$. When compared with pathological $\mathrm{T}$ staging after NACTRT, MRI achieved $86.21 \%, 57.89 \%, 75.76 \%$ and $73.33 \%$ sensitivity, specificity, PPV and NPV respectively with $75 \%$ accuracy for rectal tumor. There was no significant difference between younger individuals and older individuals in primary tumor $(\mathrm{T})$ downstaging as assessed on surgical specimen $(23.33 \%$ vs $26.31 \%$, p $=0.813)$, nodal status $(\mathrm{N})$ downstaging $(16.67 \%$ vs $0.05 \%, \mathrm{p}=0.141)$, and stage (23.33\% vs 26.31$)$.

Table 4 Pathological response-Tumour stage and Nodal stage

\begin{tabular}{|c|c|c|c|c|c|c|c|c|}
\hline \multicolumn{9}{|c|}{ Pathological T Stage (pT) } \\
\hline \multicolumn{2}{|c|}{ Clinical T Staging } & \multirow{2}{*}{$\begin{array}{l}\text { pT0 } \\
0\end{array}$} & \multirow{2}{*}{$\begin{array}{l}\text { pTI } \\
2\end{array}$} & \multirow{2}{*}{$\begin{array}{l}\text { PT2 } \\
0\end{array}$} & \multirow{2}{*}{$\begin{array}{l}\text { pT3 } \\
0\end{array}$} & \multirow{2}{*}{$\begin{array}{l}\text { pT4 } \\
0\end{array}$} & \multirow{2}{*}{$\begin{array}{l}\text { Unknown } \\
0\end{array}$} & \multirow{2}{*}{$\begin{array}{l}\text { Grand Total } \\
2\end{array}$} \\
\hline -TI & $\mathrm{N}$ & & & & & & & \\
\hline CII & $\%$ & $0.00 \%$ & $100.00 \%$ & $0.00 \%$ & $0.00 \%$ & $0.00 \%$ & $0.00 \%$ & $100.00 \%$ \\
\hline \multirow{2}{*}{ cT2 } & $\mathrm{N}$ & 5 & 1 & 4 & 15 & 2 & 0 & 27 \\
\hline & $\%$ & $18.52 \%$ & $3.70 \%$ & $14.81 \%$ & $55.56 \%$ & $7.41 \%$ & $0.00 \%$ & $100.00 \%$ \\
\hline \multirow{2}{*}{ cT3 } & $\mathrm{N}$ & 15 & 4 & 17 & 64 & 6 & 2 & 108 \\
\hline & $\%$ & $13.89 \%$ & $3.70 \%$ & $15.74 \%$ & $59.26 \%$ & $5.56 \%$ & $1.85 \%$ & $100.00 \%$ \\
\hline \multirow{2}{*}{ cT4 } & $\mathrm{N}$ & 2 & 2 & 4 & 11 & 1 & 0 & 20 \\
\hline & $\%$ & $10.00 \%$ & $10.00 \%$ & $20.00 \%$ & $55.00 \%$ & $5.00 \%$ & $0.00 \%$ & $100.00 \%$ \\
\hline \multirow{2}{*}{$\mathrm{cTx}$} & $\mathrm{N}$ & 0 & 0 & 0 & 2 & 0 & 0 & 2 \\
\hline & $\%$ & $0.00 \%$ & $0.00 \%$ & $0.00 \%$ & $100.00 \%$ & $0.00 \%$ & $0.00 \%$ & $100.00 \%$ \\
\hline \multirow{2}{*}{ Grand Total } & $\mathrm{N}$ & 22 & 9 & 25 & 92 & 9 & 2 & 159 \\
\hline & $\%$ & |3.84\% & $5.66 \%$ & $15.72 \%$ & $57.86 \%$ & $5.66 \%$ & $1.26 \%$ & $100.00 \%$ \\
\hline
\end{tabular}

\begin{tabular}{|c|c|c|c|c|c|c|}
\hline \multicolumn{7}{|c|}{ Pathological Nodal Staging (pN) } \\
\hline \multicolumn{2}{|c|}{ Clinical Nodal Staging } & \multirow{2}{*}{$\begin{array}{l}\text { pNO } \\
43\end{array}$} & \multirow{2}{*}{$\begin{array}{l}\text { pNI } \\
I I\end{array}$} & \multirow{2}{*}{$\begin{array}{l}\text { pN2 } \\
7\end{array}$} & \multirow{2}{*}{$\begin{array}{l}\text { Unknown } \\
0\end{array}$} & \multirow{2}{*}{$\begin{array}{l}\text { Grand Total } \\
61\end{array}$} \\
\hline & $\mathrm{N}$ & & & & & \\
\hline cNO & $\%$ & $70.49 \%$ & $18.03 \%$ & $11.48 \%$ & $0.00 \%$ & $100.00 \%$ \\
\hline \multirow{2}{*}{$\mathrm{cNI}$} & $\mathrm{N}$ & 42 & 11 & 15 & 2 & 70 \\
\hline & $\%$ & $60.00 \%$ & $15.71 \%$ & $21.43 \%$ & $2.86 \%$ & $100.00 \%$ \\
\hline \multirow{2}{*}{$\mathrm{cN} 2$} & $\mathrm{~N}$ & 8 & 13 & 4 & 0 & 25 \\
\hline & $\%$ & $32.00 \%$ & $52.00 \%$ & $16.00 \%$ & $0.00 \%$ & $100.00 \%$ \\
\hline \multirow{2}{*}{$\mathrm{cNx}$} & $\mathrm{N}$ & 2 & 1 & 0 & 0 & 3 \\
\hline & $\%$ & $66.67 \%$ & $33.33 \%$ & $0.00 \%$ & $0.00 \%$ & $100.00 \%$ \\
\hline \multirow{2}{*}{ Grand Total } & $\mathrm{N}$ & 95 & 36 & 26 & 2 & 159 \\
\hline & $\%$ & $59.75 \%$ & $22.64 \%$ & $16.35 \%$ & $1.26 \%$ & $100.00 \%$ \\
\hline
\end{tabular}

\section{Sphincter preservation with neoadjuvant chemoradiation}

There were 163 patients who underwent surgery, amongst whom 4 patients who did not undergo prior NACTRT were excluded. A significant proportion of patients enjoyed colostomy free life as a consequence of down-staging by neo-adjuvant chemo-radiation. Combining all 159 patients the sphincter preservation rate was $38.2 \%$. There was no significant difference in sphincter preservation rate between the younger individuals and older individuals $(39.6 \%$ vs $35.85, \mathrm{p}=0.702$ ).

\section{Survival analysis}

The mean follow up duration was 21.35 months (range, 0 to 86.86 months) in younger individuals and 20.70 months (range, 0 to 80.39 months) in older individuals. The median DFS was 54.46 months (95\% CI, 41.65-67.26) in younger individuals and 59.59 months $(95 \%$ CI, 13.39-105.80) in older individuals, a non-significant difference in
DFS distribution $(\mathrm{p}=0.622)$. There was no significant difference in 3 years DFS between younger and older individuals (63.8\% vs $66.9 \%$ respectively, $\mathrm{p}=0.821$ ), and 5 years DFS between younger and older individuals $(26.6 \%$ vs $44.6 \%$ respectively, $\mathrm{p}=0617)$. The median OS was 56.83 months (95\% CI, 51.94-80.04) in younger individuals and 65.99 months $(95 \% \mathrm{CI}, 33.10-98.88)$ in older individuals, a non-significant difference in OS distribution $(p=0.968)$. There was no significant difference in 3 years OS between younger and older individuals ( $66 \%$ vs $71.8 \%$ respectively, $\mathrm{p}=0.745)$, and 5 years OS between younger and older individuals $(49.5 \%$ vs $64 \%$ respectively, $\mathrm{p}=0.668)$.

In univariate Cox regression model, pretreatment CEA level, nodal status and clinical stage were found to be significantly affecting DFS. Multivariate Cox proportional hazards regression analysis revealed none of the above mentioned factors significantly associated with DFS. In univariate Cox regression model, pretreatment CEA level, nodal status and clinical stage were found to be significantly affecting OS. Multivariate Cox proportional hazards regression analysis 
revealed none of the above mentioned factors significantly associated with OS. Notably, age group categorization (younger and older) done for the purpose of this research was found to be neither affecting DFS nor OS.

\section{Discussion}

Over the recent years, the incidence of rectal carcinoma in older adults has been increasing, while its incidence in the young less than 50 years has been silently rising. ${ }^{3,8}$ The incidence of CRC in the United States, in both men and women under the age of 50 has been found to increase at a rate of 2 percent per year from 1992 through 2013. ${ }^{9}$ In the 1987-2006 SEER data, there was an increase in the incidence of colon and rectal cancer in people aged 20 and 49 years (10.7 per 100,000 population in 1988 and 17.9 per 100,000 population in 2006), with the sharpest increase seen among individuals 40 to 44 years of age. ${ }^{10,11}$ We found, $52.84 \%$ of patients were 50 years or younger than 50 years. Most of the younger patients were between 41 and 50 years. Age criterion for defining young-onset rectal cancers varied in different studies. We selected 50 years as the cutoff age, because 50 years is the recommended time point for initial screening in most screening programs. ${ }^{12}$ To date, the number of studies using 50 years as cutoff age has progressively increased. ${ }^{13}$ Hence it seemed logical to define young-onset as those belonging to age of 50 years or younger. Poorly differentiated adenocarcinoma was seen more frequently $(13 \%)$ in younger patients. Mucinous and signet ring cell histological variants were significantly higher in the young (11.5\% and $16.1 \%$, respectively) than in the old ( $6 \%$ and $1.7 \%$, respectively). According to other data, mucinous and signet ring subtypes were more commonly found in younger than older patients, although the differences were relatively small $(12.6 \%$ vs. $10.8 \%, \mathrm{p}<0.001) .{ }^{14}$ The SEER data (19911999) also revealed that younger patients were more likely than older patients to have mucinous and signet cell rectal tumors $(15.7 \%$ and $3.8 \%$, respectively). According to various publications, up to $30 \%$ of colorectal carcinomas may have a hereditary association with identifiable genetic aberration, especially among the young who tend to have a positive family history. ${ }^{15}$ In their study though, Mork et al., ${ }^{16}$ remarked that up to $20 \%$ of patients with a germ line mutation may not present with any family history of CRC. ${ }^{16}$ Family history of colorectal carcinomas was seen in $6.92 \%$ of our younger patients and lesser $(2.58 \%)$ in the older patients. This difference could have been the result of ignorance among people about hereditary linkage of cancer and many cancers going unnoticed and untreated in the past.

Consistent with our study, rectal carcinoma in young patients has been seen to present in advanced stages with rectal bleeding, abdominal pain, and alterations in bowel habits. ${ }^{17}$ In our data, $70.7 \%$ of the young had stage III disease at diagnosis, while only $48.2 \%$ of their older counterparts presented with this stage. This figure is much higher than in many other foreign studies (Figure 1). ${ }^{18,19}$

It is still unclear why such large proportions of our young individuals present with advanced stage disease. It could be attributed to an aggressive tumor biology, or lack of clinical suspicion, and hence more likelihood of being missed by the physician. Another possible explanation is the emergence of unfavorable dietary patterns and adoption of western lifestyle by children and young adults. Widespread use of alcohol, smoking, and obesity that are associated with these changing patterns of life in the young, are predisposing factors of CRCs. Conservative social backdrop, seeking non-traditional methods of symptom relief, such as Ayurveda and traditional Chinese medical treatments are unique to our country that may play a role in delayed diagnosis. A symptomatic young patient may procrastinate seeking medical advice for a long period due to lack of knowledge about the disease and about the potential seriousness of his/her symptoms. Additionally, in younger individuals, denial of symptoms, embarrassment, psychological issues, financial difficulties, and limited social support may also contribute to delays in presentation for symptom evaluation. It is now widely accepted that screening programs are the single most valuable tools for decreasing the incidence of a disease in any population. However, unfortunately most screening programs are recommended for the older population, and are less availed by the young. As a result, only a small proportion of the young onset cancers would be diagnosed early through screening initiatives. From 1990 to 2010, adherence to screening had increased to approximately $65 \%$ for individuals 50 to 70 years of age, which reflected in the decrease in incidence [20] of colorectal carcinomas.
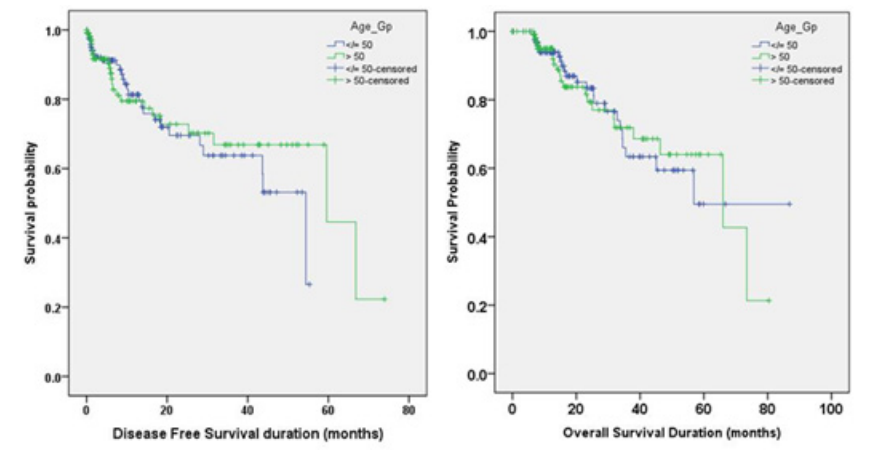

Figure I Kaplan Meier curve comparing DFS and OS distribution between the younger and older individuals.

MRI was used to assess radiological response after NACTRT. We have preferred high resolution MRI for both initial and post-treatment assessments because it allows better evaluation of the entire meso rectum and lymph nodes. Such resolution could therefore enable selective offering of NACTRT to patients with (1) large volume tumors that could potentially invade the mesorectal fascia, (2) significant lymph node involvement, or (3) signs of venous invasion.

Various studies have reported poorer prognosis of rectal carcinoma in young than in older patients. This has been explained by the more advanced disease at diagnosis, higher tumor stage, ${ }^{22,23}$ more mucinous or signet-ring histopathology, and poorly differentiated tumors. ${ }^{23}$ However, in spite of the poor prognostic factors in our study, pathological complete response (T0N0) was more in the young $(16.81 \%$ vs $10.91 \%)$ and younger patients were more likely to complete the full treatment in the form of NACTRT, surgery, and adjuvant chemotherapy as compared to older patients (70\% vs. $56 \%)$. A study by Luis J García-Flórez also showed similar pathological complete response rates. ${ }^{24}$ Inspite of this there was no significant differences in either DFS or OS between the younger and the older patients in our study. This makes us think that given the higher comorbidities and lesser likelihood of completing their treatment in older individuals, the younger patients can probably have a better survival if they are diagnosed earlier at a less advanced stage. Pretreatment CEA level, nodal status and clinical stage were found to be the only factors significantly affecting the OS.

There are considerable variations in the reported survival of young rectal cancer patients in studies across continents. One reason for this difference could be the lack of any accepted definition of "young". While there are studies that have reported a poorer prognosis for younger cancers, ${ }^{25}$ some studies did not show any difference in survival between both age groups after adjusting for confounding 
factors. ${ }^{26,27}$ Ruiz et al. ${ }^{28}$ showed an overall survival rate of $67.4 \%$ at 5 years for young rectal cancer patients. Parc et al. reporting survival data from central South Korea also revealed a 5-year survival of $66 \%$ in young patients with rectal cancer. ${ }^{28}$

The strong point in our study, we feel is our attempt to study and compare all the main parameters including tumor characteristics, response, sphincter sparing rates and survival between the two age groups of rectal carcinoma. We have also tried to correlate the pathological outcomes with the radiological outcomes. But, being carried out in an institute, catering to a heterogenous socioeconomic cross section of the society, there were many patients who could not afford radiological tests during the treatment course and this proved to be a limitation of our research work. The toxicities during the treatment were not mentioned as we thought that this was not the focus of our study.

\section{Conclusion}

Young onset rectal cancer with a rising incidence is characterized by advanced stage disease at presentation, aggressive histopathological features, and relatively poor response to treatment. Special screening protocols, educational activities, lifestyle modification customized to Indian infrastructure are urgently needed to deal with this formidable situation. A high index of clinical suspicion is warranted for early diagnosis and initiation of therapy. Stringent evaluation is imperative if an individual has positive family history in addition to the prolonged symptoms. Whether escalation of therapy is needed or will have any benefit is a question that needs rigorous research, and well conducted prospectively designed randomized controlled trials.

\section{Acknowledgments}

The authors would like to thank "Ramesh Nimmagadda Cancer Foundation" for their technical support with Onco Collect for the collection and analysis of data.

\section{Conflicts of interest}

The author declares that there is no conflict of interests regarding the publication of this paper.

\section{References}

1. Atkin WS, Cuzick J, Northover JM, et al. Prevention of colorectal cancer by once-only sigmoidoscopy. Lancet. 1993;341(8847):736-740.

2. Torre LA, Bray F, Siegel RL. Global cancer statistics, 2012. CA Cancer J Clin. 2015;65(2):87.

3. Siegel RL, Miller KD, Jemal A. Cancer Statistics, 2017. CA Cancer J Clin. 2017;67:7.

4. Chew MH, Koh PK, $\mathrm{Ng} \mathrm{KH}$, et al. Improved survival in an Asian cohort of young colorectal cancer patients: an analysis of 523 patients from a single institution. Int J Colorectal Dis. 2009;24(9):1075-1083.

5. Adloff M, Arnaud JP, Schloegel M, et al. Colorectal Cancer in Patients Under 40 Years of Age. Dis Colon Rectum. 1986;29(5):322-325.

6. O’Connell JB, Maggard MA, Liu JH, et al. Do Young Colon Cancer Patients Have Worse Outcome? World J Surg. 2004;28(6):558-562.

7. Pahlavan PS, Kanthan R. The Epidemiology \& clinical findings of colorectal cancer in Iran. J Gastointest liver Dis. 2006; 15(1):15-19.

8. Davis DM1, Marcet JE, Frattini JC, et al. Is it time to lower the recommended screening age for colorectal cancer? J Am Coll Surg. 2011;213(3):352-361.
9. National Cancer Institute. Division of Cancer Control and Population Sciences, Surveillance Research Program, Surveillance Systems Branch; 2016.

10. Horner MJ, Ries LAG, Krapcho M, et al. SEER Cancer Statistics Review, 1975-2006. National Cancer Institute: Bethesda, USA; 2009.

11. Davis DM, Marcet JE, Frattini JC, et al. Is it time to lower the recommended screening age for colorectal cancer? J Am Coll Surg. 2011;213(3):352-362

12. Levin B, Lieberman DA, McFarland B, et al. Screening and surveillance for the early detection of colorectal cancer and adenomatous polyps, 2008: a joint guideline from the American Cancer Society, the US MultiSociety Task Force on Colorectal Cancer, and the American College of Radiology. CA Cancer J Clin. 2008;58(3):130-160.

13. Siegel RL, Fedewa SA, Anderson WF, et al. Colorectal Cancer Incidence Patterns in the United States, 1974-2013. J Natl Cancer Inst. 2017;109(8).

14. You YN, Xing Y, Feig BW, et al. Young-Onset Colorectal Cancer: Is It Time to Pay Attention? Arch Intern Med. 2012;172(3):287-289.

15. Slattery ML. Diet, lifestyle, and colon cancer. Semin Gastrointest Dis. 2000;11:142-146.

16. Mork ME, You YN, Ying J, et al. High Prevalence of Hereditary Cancer Syndromes in Adolescents and Young Adults with Colorectal Cancer. $J$ Clin Oncol. 2015;33:3544-3549.

17. Taggarshe D, Rehil N, Sharma S, et al. Colorectal cancer: are the "young” being overlooked? Am J Surg. 2013;205(3):312-316.

18. Ganapathi S, Kumar D, Katsoulas N, et al. Colorectal cancer in the young: trends, characteristics and outcome. Int $J$ Colorectal Dis. 2011;26(7):927-934.

19. You YN, Dozois EJ, Boardman LA, et al. Young-onset rectal cancer: presentation, pattern of care and long-term oncologic outcomes compared to a matched older-onset cohort. Ann Surg Oncol. 2011;18(9):2469-2476.

20. Edwards BK, Ward E, Kohler BA, et al. Annual report to the nation on the status of cancer, 1975-2006, featuring colorectal cancer trends and impact of interventions (risk factors, screening, and treatment) to reduce future rates. Cancer. 2010;116(3):544-573.

21. Fu J, Yang J, Tan Y, et al. Young patients $(</=35$ years old $)$ with colorectal cancer have worse outcomes due to more advanced disease: 30-year retrospective review. Medicine. 2014;93(23):e135.

22. Ben-Ishay O, Brauner E, Peled Z, et al. Diagnosis of colon cancer differs in younger versus older patients despite similar complaints. Isr Med Assoc J. 2013;15(6):284-287.

23. Keswan SG, Boyle MJ, Maxwell JP, et al. Colorectal cancer in patients younger than 40 years of age. The American surgeon. 2002;68(10):871-876.

24. García-Flórez LJ, Gómez-Álvarez G, Frunza AM, et al. Response to chemo radiotherapy and lymph node involvement in locally advanced rectal cancer. World J Gastrointest Surg. 2015;7(9):196-202.

25. Li M, Li JY, Zhao AL, et al. Do young patients with colorectal cancer have a poorer prognosis than old patients? J Surg Res. 2011;16(2):231-236.

26. Yeo SA, Chew MH, Koh PK, et al. Young colorectal carcinoma patients do not have a poorer prognosis: a comparative review of 2,426 cases. Tech Coloproctol. 2013;17(6):653-661.

27. Lee PY, Fletcher WS, Sullivan ES, et al. Colorectal cancer in young patients: characteristics and outcome. Am Surg. 1994;60(2):607-612.

28. Park HC, Shin A, Kim BW, et al. Data on the characteristics and the survival of korean patients with colorectal cancer from the Korea central cancer registry. Ann Coloproctol. 2013;29(4):144-149. 